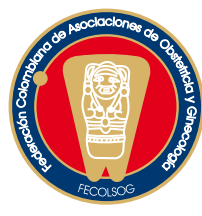

\title{
Editorial
}

\section{SECCIÓN COLOMBIA DEL AMERICAN COLLEGE OF OBSTETRICIANS AND GYNECOLOGISTS (ACOG) Y PROCESO DE RECERTIFICACIÓN VOLUNTARIA}

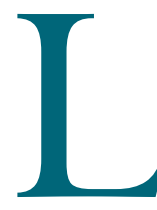

a Federación Colombiana de Asociaciones de Obstetricia y Ginecología (FECOLSOG), ha venido trabajando los últimos años en el científicos con sociedades científicas y gremiales en todo el continente, que permitan fortalecer y diversificar las oportunidades académicas que requieren los ginecólogos del país, en Colombia y fuera de ella.

Dentro de este proceso, el pasado 26 de febrero, se consolidó el trabajo que desde hace 3 años se estaba realizando con el American College of Obstetricians and Gynecologists (ACOG), con el fin de crear la sección colombiana de ACOG. Dicha sección fue conformada con 40 Miembros Fundadores, Ginecólogos de todo el país, que participaron en una reunión final con representantes de ACOG; a partir de este momento y una vez se reciba la aprobación oficial de la Presidencia de ACOG, todos los Gineco-obstetras miembros de FECOLSOG pueden afiliarse a ACOG por medio de la Sección Colombia, tal como se ha realizado en Centroamérica y en Chile.

Los requisitos para vincularse a ACOG son básicamente dos: presentar y aprobar un examen que pretende evaluar los objetivos educacionales que se consideran necesarios para un Gineco-obstetra y ser egresado de una universidad avalada por el proceso de acreditación FECOLSOG - ACOG. Durante los dos primeros años, y mientras se desarrollan ambos procesos, todos los Gineco-obstetras de FECOLSOG pueden solicitar esta vinculación, haciéndose Fellows de ACOG y teniendo derecho a las ventajas que tienen los FACOG (Fellows de ACOG), entre las que se encuentran:
- Acceso a la sección para miembros del sitio en la red de ACOG

- Reunión clínica anual

- Programa audiovisuales

- Programa de recertificación

- Directorio de miembros

- Avisos de codificación / avisos económicos

- Materiales educativos y opiniones con respecto a los avances en la práctica clínica

- Donaciones / becas / premios

- Directrices para la atención perinatal

- Directrices para la atención médica de la mujer

- Programa de Préstamos para Educación Superior (HELP)

- Interacciones

- Planes de seguros (a bajo costo)

Como parte del continuo compromiso de ACOG con la educación, a los miembros se les ofrece una amplia variedad de publicaciones:

1. Obstetrics \& Gynecology también conocida como "Green Journal". Es la revista oficial de ACOG

2. ACOG Clinical Review. Es una publicación bimestral que incluye resúmenes de literatura actual seleccionada en el campo de la ginecología y la obstetricia.

3. Primary Care Update Journal. Brinda información actual en atención primaria y preventiva para la mujer.

4. ACOG Today (boletín). Ofrece información oportuna acerca de las actividades y programas de la Asociación y acerca de temas de actualidad en la especialidad.

5. Compendio de publicaciones selectas. El Compendio es una recopilación de directrices 
selectas de ACOG sobre la práctica clínica. Es una invaluable referencia a áreas esenciales de la especialidad. El compendio incluye documentos de Opiniones de Comités, Boletines Educativos y Técnicos, Boletines de la Práctica y Patrones de la Práctica.

6. Directorio de miembros de ACOG. Se publica cada dos años y consiste en un listado actualizado de todos los Miembros, incluyendo una guía de los funcionarios y comités de ACOG.

7. División de ACOG para temas de salud de la mujer. Ofrece recursos a los miembros sobre temas como el acceso a la atención para las menos privilegiadas, atención médica para adolescentes, prevención de embarazos, violencia doméstica y otros temas especiales.

8. Centro de Recursos de ACOG. La biblioteca de la Asociación, ofrece búsquedas de cortesía en MEDLINE, fotocopias de artículos de la colección y realiza investigación para los miembros de ACOG. Los bibliotecarios brindan ayuda para encontrar y usar recursos en la Internet.

9. Sitio de ACOG en la World Wide Web. Brinda una gran riqueza de información y ayuda a la comunidad electrónica. Los miembros pueden encontrar el texto completo de las publicaciones de ACOG, como también búsquedas en MEDLINE y otras bases de datos médicos.

10. Opiniones sobre ética. Consisten en discusiones y recomendaciones o correspondencia informal para ayudar a los Miembros a solucionar dilemas de naturaleza ética que encuentran en la práctica de la ginecología y la obstetricia.

11. Cartillas o panfletos para la educación de pacientes, que por lo general se desarrollan en temas variados. Estos panfletos están a disposición para que sirvan como guía para responder a preguntas de pacientes.

12. Programa para la Continuación del Desarrollo Profesional (Programa de Recertificación). Brinda una lista anual de las actividades de Educación Médica Continua.
13. Manual de Evaluación de Calidad. Tiene el objetivo principal de ayudar a los departamentos de ginecología y obstetricia de los hospitales en la evaluación de la calidad de la atención que brindan.

Después de estos dos años, las personas que ingresen deben presentar y aprobar el examen que está en desarrollo por parte del Comité de Acreditación FECOLSOG - ACOG, y además ser egresados de universidades que hayan realizado el proceso de Acreditación establecido por el Comité, bajo las recomendaciones de ACOG; esta acreditación busca acompañar y apoyar a los programas de Postgrado para que sus residentes cumplan las competencias que debe tener un Gineco-obstetra de hoy.

Para los médicos Residentes, desde su primer año, existe la posibilidad de vincularse en la modalidad de Junior Fellows, lo que les permite tener los beneficios, a menor costo, mientras terminan su programa de Especialización, para luego tener la posibilidad de presentar el examen y vincularse como Fellows.

Paralelo a este proceso, FECOLSOG ha lanzado el programa de recertificación voluntaria de la ginecoobstetricia, el cual busca que los Ginecólogos tengan una amplia variedad de posibilidades para mantenerse actualizados por medio de actividades académicas que se acomoden a las diferentes necesidades de acuerdo al tiempo disponible, al sitio de residencia y a las preferencias académicas de cada uno. El concepto de la recertificación se ha impuesto en diversos países, ante la necesidad creciente de mantenerse actualizado en una profesión de constante cambio y de responsabilidad social inmensa; no podemos seguir viendo la Recertificación como algo incómodo que nos pone trabas sino, al contrario, como una estrategia de posibilidades y herramientas que nos ayuda a mantener un ejercicio médico más competitivo y con estándares de calidad adecuados, en medio de una cada vez mayor competencia, donde estos procesos pueden constituirse en el factor diferencial a nuestro favor.

FECOLSOG trabaja por nosotros.

Jimmy Castañeda, M.D.

Presidente FECOLSOG 